Recepción: 30/10/2018

Aprobación: 06/11/2018

Reseña de libro

DOI: https://doi.org/10.22267/rhec.192222.58

\title{
Cardona Zuluaga, Patricia. Trincheras de tinta: la escritura de la Historia patria en Colombia, 1850-1908. (Medellín: Fondo Editorial Universidad EAFIT, 2016), 380
}

\section{Jorge Alejandro Aguirre Rueda ${ }^{1}$}

Instituto de Investigaciones Dr. José María Luis Mora, México

La cuestión por la manera en que se buscó materializar dos ideas difusas en la segunda mitad del siglo XIX como lo eran nación y patria, tuvo en las denominadas obritas de historia uno de sus elementos que propendieron por tal fin. Esta idea es directriz en el trabajo realizado por Cardona Zuluaga quien señala que en el centro de estos "libros más

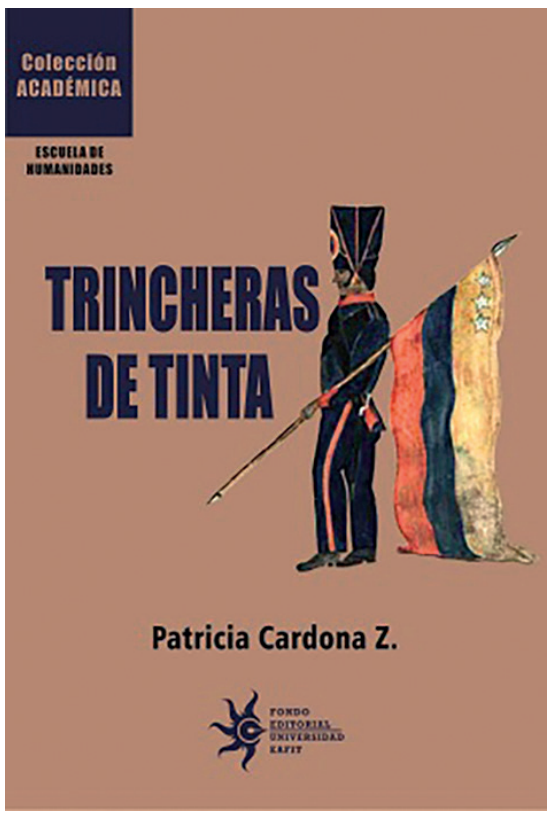
sencillos y pequeños" se encontraba el "cimentar las bases históricas de una narrativa consensuada en la construcción de los lazos nacionales y en la exaltación del pasado como fundamento de la formación cívica necesaria en la extensión de la "fratría" nacional [...]". Así, las obritas junto con la Historia Patria en el periodo de estudio no fueron única y exclusivamente representaciones discursivas, sino que se erigieron en mecanismos culturales que "cumplieron a cabalidad la función de dar a la patria una materialización precisa, una forma concreta [...]"2.

La autora discute en el capítulo cuarto titulado La Historia patria. Retórica, formatos y usos con el historiador Germán Colmenares, su tan mentada aseveración de la existencia de lo que él concebía como una prisión historiográfica. Así, y a contracorriente de los seguidores de Colmenares, Cardona Zu-

\footnotetext{
$1 \quad$ Estudiante del programa de doctorado en Historia Moderna y Contemporánea. Instituto de Investigaciones Dr. José María Luis Mora, México. Línea de investigación: Historia de la Educación en Colombia. Correo electrónico: jorgealejandroaguirrerueda57@gmail.com. Código ORCID: https://orcid.org/0000-0001-6988-3620

2 Cardona Zuluaga, "Trincheras de tinta", 16-19
} 
luaga apunta a corregir el fallo: "esas interpretaciones adolecen de una mirada eminentemente discursiva" además de carecer "de la fuerza suficiente para entender las condiciones de escritura [...] y del incipiente mundo editorial que fueron decisivas en los modos de escritura y de lectura de los libros de historia"3. Asimismo, otra discusión que adelanta la autora -considerada relevante para la historia de la educación y el campo de la historia de las disciplinas escolares- se enmarca en criticar aquellas posturas que estudian libros -y especialmente los de historia patria- "según modelos analíticos que suponen la imposición cultural e ideológica de los grupos dominantes sobre los dominados". Por lo tanto, someter la explicación de la emergencia y aparición de un libro de historia patria y de las obritas desde un "horizonte instrumentalista que los reduce a simples herramientas ideológicas", es sencillamente negarles su carácter de "forma específica de saber" o "ámbito de saber" y otearlos como la muestra exaltada de una "ideología"

Con esta estructura de investigación, a la cual se suma el enfoque de la materialidad desarrollada por la obra de Donald F. McKenzie e igualmente la noción de refiguración avanzada por Paul Ricoeur, entre otros autores mencionados en el libro, Cardona Zuluaga pone a consideración el resultado -con algunas transformaciones- de su pesquisa adelantada en el Doctorado en Historia en la Universidad de los Andes (Colombia). El libro, compuesto por la Introducción, cinco capítulos, una Síntesis y Conclusiones, se considera relevante en un momento en donde el escueto análisis de los contenidos de textos impera en los trabajos sobre obras escritas como por ejemplo los libros y manuales escolares.

El primer capítulo titulado Formatos y saberes: condiciones epistémicas de la Historia patria, tiene el acierto de señalar que "entendemos por libro de historia no solo el objeto material, sino también las diferentes relaciones sociales que se cruzan en una publicación de este tipo". Relaciones que pasaban por la confluencia entre contenidos, escritores, formas de indagación, elaboración de la narración histórica y los diferentes públicos. Públicos que ciertamente obedecían a una tradición editorial ante lo cual era común que se encontrasen formatos del texto escrito en donde novenas, catones, silabarios, cartillas, compendios, entre

\footnotetext{
3 Cardona, "Trincheras de tinta", 256.

4 Cardona, "Trincheras de tinta", 211-212.
} 
otros, eran la norma. Ante el olvido y menosprecio en que han caído formatos como las cronologías, Cardona Zuluaga pone de relieve el papel e importancia que llegaron a tener en la "construcción de una idea de tiempo "nacional"”s.

Sin embargo, este capítulo se resiente toda vez que ante aseveraciones interesantes y sugerentes como el llamar la atención sobre la destinación de libros a los saberes de la geografía, la gramática y la moral, la autora no haya podido disponer de información que mostrara lo concerniente al tema material de dichos libros como fueran aspectos ligados a la producción, distribución, comercialización. Ahora bien, se puede controvertir esta demanda si se apela a la misma Cardona Zuluaga: "nos ha interesado explorar la materialidad más en función de los tamaños y densidad de los volúmenes y contenidos, y no desde la perspectiva tipográfica o de las particularidades de editores e impresores".

Con Historia y divulgación: formas, usos y públicos, logra Cardona Zuluaga poner en consideración -bien logrado desde nuestro punto de vista- la relación de bisagra que existió entre el mundo de los saberes retóricos y la escritura de la historia que venía caminando sobre nuevos pasos y exigencias. Así, este segundo capítulo señala la necesidad de entender que la retórica "fue un medio para hacer claro el discurso y, a su vez, el punto de partida que permitió la legibilidad de los estudios históricos que empezaban a surgir". Legibilidad que entre 1850 hasta 1910 se vio funcionando en paralelo con las innovaciones que el conocimiento histórico venía adelantando, tales como la aparición de "una serie de procedimientos y prácticas que, sustentados en la crítica y en los postulados de la razón y de la ciencia, invocaban la prueba documental autenticada como vía para acceder a un conocimiento objetivo y exacto del pasado"7. Este movimiento es de suma importancia puesto que coloca la investigación histórica colombiana en un marco geográfico más amplio. Tal como lo remarca Ivan Jablonka - guardando las proporciones para nuestra realidad- "en los últimos veinticinco años del siglo XIX tiene lugar en Europa y América del Norte una revolución intelectual que incorpora la "ciencia positiva". [...] La ciencia histórica que triunfa a fines del siglo XIX descansa sobre tres pilares: el ideal de objetividad, la fuente documental y el medio profesional"s.

Cardona, "Trincheras de tinta", 41-43.

Cardona, "Trincheras de tinta", 15.

Cardona, "Trincheras de tinta", 123.

Ivan Jablonka, La historia es una literatura contemporánea. Manifiesto por las ciencias sociales, (Argentina: Fondo de Cultura Económica, 2016, 2014, primera edición en francés), 81-82. 
Un segundo elemento a resaltar en este capítulo número dos, concierne al hallazgo que realiza Cardona Zuluaga en el tema que atañe a la introducción de un ideario que además de "conocer e indagar el pasado", le permitiese a la historia "construir un conocimiento explicativo focalizado en el avance de civilización y del progreso, que convergía en una noción del futuro como temporalidad aprehensible, gracias a que el conocimiento del pasado facilitaba una previsión racional del tiempo por venir"'. Ahora bien, lo que debemos retener es la larga presencia de una noción como progreso tal como lo ha dejado ver Jorge Orlando Melo quien nos recuerda que: "la idea de que la sociedad en su conjunto puede mejorar, y que esto incluye no solo mejoras concretas y discretas sino un proceso integral, en el que están estrechamente relacionados los avances de la educación, el conocimiento, el derecho y la organización política, las artes y la producción, aparece solo a finales del siglo XVIII, se impone durante el siglo XIX y mantiene su fuerza hasta hoy"10.

Sin embargo, el aspecto que más se echa de menos en este capítulo es uno que ya había sido presentado en las páginas iniciales del texto y que se retoma en el subtítulo del capítulo: la cuestión del público. Expuesta la idea por Cardona Zuluaga según la cual las obritas no debían ser catalogadas exclusivamente en su condición de textos de uso escolar, "pues hemos procurado insertarlos en un campo más vasto: el de publicaciones para las mayorías, que convocaban a diversos segmentos sociales y de las cuales podían participar tanto los letrados como los no letrados", terminaba enfáticamente señalando que "si bien destinada a la enseñanza, no circunscribía sus alcances a la escuela. Las obritas buscaban llegar a toda la sociedad, a través de la lectura directa e individual, así como de la oralización grupal de sus contenidos"11. Se resentirá el lector al encontrar que no hay una descripción o acercamiento somero a las mayorías mencionadas, o al desarrollo de nociones tales como "toda la sociedad", o acaso a una breve delineación de lo que pudo haber sido y significado ya la "lectura individual" o acaso "la oralización grupal de sus contenidos" que menciona la autora.

Llegados a Las obritas de Historia patria. Homogeneización ética, concordia y pasión, logra este tercer capítulo evidenciar que el uso continuo de las "tradiciones épicas" contenidas en los relatos históricos obedeció a la misma for-

\footnotetext{
9 Cardona, "Trincheras de tinta", 129-130.

10 Melo, La idea de progreso en el siglo XIX, ilusiones y desencantos, 3.

11 Cardona, "Trincheras de tinta", 19, 100.
} 
mación académica de los escritores, aparejado a la función asignada a la Historia patria: "narrar acciones heroicas y de inmortalizar a los hombres y a las colectividades que participaron en ellas". Sin embargo, Cardona Zuluaga advierte sobre no instrumentalizar o ideologizar dicha tradición épica, para lo cual pone sobre aviso y recuerda que "más bien hay que pensar que la sociedad estaba -por razones históricas, por la frecuente alusión a gestar tanto en la tradición oral profana como en la sagrada- familiarizada con la épica, que comprendía sus relatos y que entendía claramente los móviles de las hazañas, la justicia de las acciones y los vicios y las virtudes que encarnaban los personajes" 12 . Un importante y segundo acierto y logro de este capítulo es el señalar que la escritura de las obritas de historia patria estuvo más o menos ajena a las ideologías partidistas, para lo cual señala la labor adelantada por el conservador José María Quijano Otero quien fuese contratado por el mismo gobierno liberal-radical en el año de 1872 para escribir su Compendio de historia patria ${ }^{13}$. Sin embargo, otro recelo y vacío que encontrará el lector en este capítulo reside en la promesa incluida y al final fallida de la autora, cuando señaló con atino que una de las dimensiones materiales de la aparición de las obritas radicaba precisamente en sus "asuntos técnicos y económicos". A la sazón, aparecerán frases como "modesto mercado impreso", "obtener ganancias", "mercado rentable", "agente vendedor de libros", "librero" y finalmente, "negocios editoriales", las cuales infortunadamente no logran al menos una rápida descripción por parte de la autora, más allá de la mención a ciertos contratos realizados por escritores como José Joaquín Borda.

Finalmente, Cardona Zuluaga en su capítulo 5 titulado Sobre escritores de obritas y mercado de libros ofrece una mirada más ponderada en relación al periodo de la historia colombiana conocido como la Regeneración. Mayoritariamente señalado como un lapso en donde supuestamente se accionó "un freno en materia educativa y específicamente en el campo de la producción y expansión del mercado de libros", la autora contrasta dicha afirmación con el hecho cierto en relación a que fue precisamente durante el proyecto regeneracionista cuando se ordena y reglamenta "la figura del autor y los mecanismos para acotar asuntos como el de propiedad literaria y la relación entre los escritores y el Estado"14. Ahora bien, una de las críticas que se le puede realizar a este capítulo final versa explícitamente al fenómeno que Cardona Zuluaga nombra en el título del apar-

\footnotetext{
12 Cardona, "Trincheras de tinta", 149-150.

13 Cardona, "Trincheras de tinta", 171-173.

14 Cardona, "Trincheras de tinta", 311.
} 
tado: el relacionado al "mercado de libros"15. Lastimosamente, la autora si bien acierta al nombrar aquel sujeto que emerge como aquella "figura moderna del autor" que se encuentra relacionada a unos "contextos de enunciación, producción y circulación", no proporciona información sobre el "mercado" a sabiendas que fue gracias a éste que las ideas pudieron ser "leídas, interpretadas y memorizadas por otros".

Así entonces, es cierto que estamos frente a una obra que a nuestro entender aporta una representación historiográfica sobre el mundo del libro sugerente y polémica, pues sabemos que las voces que aún consideran al libro de texto simple y vulgarmente como un mero dispositivo de control son numerosas y se encuentran atrincheradas en perspectivas que erróneamente siguen considerando a productos sociales como la escuela y el manual escolar desde la óptica del escueto mecanismo disciplinador.

15 Cardona, "Trincheras de tinta", 285. 